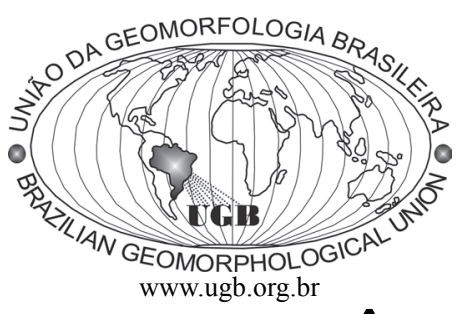

\title{
A INFLUÊNCIA DA TOPOGRAFIA NA DISTRIBUIÇÃO DE GRAMÍNEAS EM UM FRAGMENTO DE FLORESTA ATLÂNTICA URBANA MONTANHOSA - MACIÇO DA TIJUCA/RJ
}

\author{
Maria Accioly Dias \\ Mestre/PPGGeografia-UFRJ; Bolsista CAPES - Coordenação de Aperfeiçoamento de Pessoal de Nivel Superior; \\ GEOHECO/Laboratório de Geo-Hidroecologia, Departamento de Geografia, Instituto de Geociências da Universidade \\ Federal do Rio de Janeiro - Endereço: Rua Coronel Afonso Romano, 74 / 102, Botafogo, Rio de Janeiro/RJ - \\ CEP: 22281-010 - E-mail: m.accioly.dias@gmail.com
}

Ana Luiza Coelho Netto Professora Titular do Departamento de Geografia, Instituto de Geociencias da Universidade Federal do Rio de Janeiro, Coordenadora do GEOHECO/DEGEOG-IGEO-UFRJ e Pesquisadora 1A-CNPq. - Endereço: Rua Lopes Quintas, 355 apto 105 - Jardim Botânico - Rio de Janeiro/RJ - CEP: 22.460-010 - E-mail: ananetto@acd.ufrj.br

OBS: Pesquisa financiada por: CNPq (Edital Universal), FAPERJ (Edital Cientista do Estado) e CNPq-FAPERJ (Editais PRONEX e INCT-REAGEO).

\begin{abstract}
Resumo
Um importante mas ainda pouco compreendido fator de influência na dinâmica florestal em áreas montanhosas é a topografia. O objetivo deste estudo foi analisar a distribuição espacial de manchas de gramíneas no fragmento de floresta atlântica urbana que recobre o Maciço da Tijuca, levando em conta os aspectos topográficos. Foi feito um mapeamento de uso e cobertura com base em ortofotos aéreas de 2004, e, com o auxílio de um Modelo Digital de Elevação, foram realizadas algumas análises espaciais (mensuração de área em superfície real, orientação de encostas, radiação incidente e posição topográfica) e temporais (comparações entre mapeamentos realizados em 1972, 1984 e 1996 e comparações entre ortofotos de 1999 e 2004). As manchas de gramíneas e de vegetação arbóreo-arbustiva apresentaram um forte padrão de distribuição espacial, concentrando-se nas encostas voltadas para o Norte e nos divisores e altas encostas, o que foi atribuído, respectivamente, à maior incidência de radiação solar nas encostas Norte e à convergência dos fluxos de água e nutrientes dos divisores para os fundos de vale. Temporalmente, notou-se uma ligeira tendência de aumento das áreas de gramíneas nas zonas de divergência de fluxos e diminuição nas zonas de convergência. Observou-se ainda que, dentre as bacias de segunda ordem que possuíam gramíneas em 1999, 37\% mostraram significativa transformação para formações arbóreo-arbustivas em 2004 - o que provavelmente se deveu em parte aos reflorestamentos realizados nestas áreas.
\end{abstract}

Palavras-chave: Manchas de gramíneas; topografia; regeneração florestal.

\begin{abstract}
One important but seldom studied factor of influence on forest dynamics in mountainous areas is topography. The purpose of this study is to analyze the spatial distribution of grass patches in the fragment of urban forest that recovers Tijuca massif, considering topographic factors. We elaborated a land cover and use map based on aerial ortophotos taken in 2004. Then, with the support of a Digital Elevation Model, we performed a series of spatial analyses (real surface area mesurements, slope orientation, incident radiation and topographic position) and temporal analyses (comparations between previous 1972, 1984 and 1996 mappings, and between 1999 and 2004 ortophotos). Grass and shrub-tree vegetation patches presented a conspicuous distribution pattern, concentrating at north-facing slopes and at ridges and upper slopes, facts that have been
\end{abstract}


attributed to the major incidence of solar radiation at north slopes and to the convergence of water and nutrient fluxes from the slope divides towards the valley bottoms, respectively. Temporally, there was a slight tendency of increasing grass areas at divergence zones and decreasing at convergence zones. We observed also that $37 \%$ of second order basins which had grass areas in 1999 presented significant transformation from grass to shrub-tree vegetation in 2004 - which is probably related in part to reforestations performed in these areas.

Keywords: Grass patches; topography; forest regeneration.

\section{Introdução}

A acelerada expansão das áreas urbanas e agrícolas vem gerando intensas mudanças nas paisagens, acarretando degradação, retração e fragmentação dos ecossistemas naturais. Neste contexto, a maior parte das paisagens passa a ser constituída por áreas sob influência de bordas (Chen et al., 1999), o que pode ter implicações severas no funcionamento de um geoecossistema. Frente à dificuldade de conservação dos remanescentes florestais, a dinâmica de bordas florestais surgiu como tema de grande relevância dentro da Geoecologia, notadamente através do conceito de "efeito de borda", sobre o qual muitos estudos vêm sendo realizados nas últimas décadas (Murcia, 1995; Jose et al., 1996; Ferreira e Laurance, 1997; Didham, 1998; Laurance et al., 1998a; Laurance et al., 1998b; Chen et al., 1999; Sizer e Tanner, 1999; Tabarelli, Mantovani e Peres, 1999; Gascon et al., 2000; Laurance, 2000; Laurance et al., 2000; Sizer, Tanner e Ferraz, 2000; Ries et al. 2004; Baldissera e Ganade, 2005; Figueiró, 2005; Harper et al., 2005; Nelson e Halpern, 2005; Laurance et al., 2006; Nascimento e Laurance, 2006; Herbst et al., 2007; Heithecker e Halpern, 2007; Portela e Santos, 2007; Laurance, 2008; Faria et al., 2009; Gonzalez, Deconchat e Balent, 2009).

Por se tratar de uma zona de tensão entre dois (ou mais) ecossistemas adjacentes, pode-se entender que as bordas florestais apresentam uma dinâmica resultante de forças direcionais antagônicas: por um lado, o efeito de borda, que tende a causar degradação e retração da floresta ${ }^{1}$; por outro, a sucessão ecológica, que promove a regeneração florestal e pode acarretar um novo avanço da floresta sobre o sistema vizinho. No entanto, tal dinâmica implica processos complexos, que podem ser modulados por muitas variáveis e, desta forma, os controles que determinam qual direção vai predominar não são, ainda, suficientemente claros.

\footnotetext{
${ }^{1}$ Embora, a rigor, o efeito de borda seja um fenômeno de mão dupla, afetando reciprocamente os dois (ou mais) ecossistemas em contato, o termo é comumente usado de forma a enfocar as alterações no sistema de interesse, normalmente a formação vegetação original que encontra-se ameaçada. Por isso, utilizamos aqui o termo em um sentido unidirecional, considerando que tenderia a causar a retração da floresta.
}

A ênfase dos estudos sobre efeito de borda vem recaindo principalmente em aspectos como o tipo de matriz, a orientação e a idade da borda (Murcia, 1995). Segundo Jules e Priya (2003), o tipo de matriz ${ }^{2}$ pode ser considerado como um dos fatores primários na determinação da dinâmica de uma borda florestal. Em florestas urbanas, por exemplo, onde a pressão antrópica costuma gerar um complexo mosaico de usos do solo, é fácil observar que as consequências de cada tipo de vizinhança com as áreas florestais podem ser bastante diversas. Enquanto a vizinhança urbana favorece a criação de trilhas, o pisoteamento e o lançamento de lixo (Figueiró, 2005), as áreas de gramíneas são grandes potencializadoras de incêndios (Zaú, 1998; Freitas, 2001). Um estudo no Maciço da Tijuca/RJ evidenciou que $45 \%$ das ocorrências de incêndio entre 1997 e 2002 foram em áreas de gramíneas e apenas 16\% em áreas de floresta conservada. Do total de ocorrências em gramíneas, 78,3\% tinham área adjacente de uso urbano - o que indica ser esta uma interface composta extremamente vulnerável (Figueiró, 2005).

Em áreas montanhosas, um outro fator de grande influência potencial na dinâmica florestal é a topografia (que inclui aspectos como elevação, orientação, declividade e geometria de encostas e posição topográfica). Segundo Robert e Moravie (2003), variações topográficas parecem ser um dos maiores fatores geradores de heterogeneidade estrutural na floresta. Tal heterogeneidade implica particularidades em seu funcionamento, podendo ajudar a determinar a velocidade e a magnitude tanto do efeito de borda quanto da regeneração florestal. Nas últimas duas décadas, diversos estudos vêm buscando relacionar diferenças topográficas (especialmente de orientação e inclinação de encostas) a fatores ecológicos como estrutura da vegetação (Oliveira et al., 1995; Clark e Clark, 2000; Robert e Moravie, 2003; Lima e Moura, 2006), composição florística (Slik e Eicchorn, 2003; Lima e Moura, 2006; Zeleny e Chytry, 2007),

\footnotetext{
${ }^{2}$ Matriz é o termo comumente utilizado para designar o tipo de uso do solo/cobertura vegetal em que se encontra inserido um fragmento florestal. No caso da Floresta da Tijuca, que se constitui como um grande fragmento florestal com diversos tipos de uso à sua volta, o termo "matriz", em seu sentido original, não se adequa perfeitamente, mas o significado funcional permanece útil. De forma mais genérica, chamamos aqui de matriz o tipo de uso/cobertura adjacente à floresta.
} 
parâmetros de solo (Zueng-Sang Chen et al., 1997; Fox, Maselli e Carrega, 2008; Wang et al., 2009), crescimento, mortalidade e recrutamento de plântulas e juvenis (Herwitz e Young, 1994; Bellingham e Tanner, 2000; Comita et al., 2009; Li, Feng-Rui et al., 2009), suscetibilidade à formação de clareiras no dossel (Gale, 2000; Ashton et al. 2001; Lima e Moura, 2008), formação de húmus (Descheemaeker et al., 2009), padrões de distúrbio, sucessão e taxas de desenvolvimento local da vegetação (Hadley, 1994), e regeneração florestal (Yamagawa et al., 2006; Marangon et al., 2008). No contexto da dinâmica de bordas, porém, a topografia é ainda escassamente investigada.

Na Mata Atlântica, as variáveis topográficas ganham relevância especial, pois a maioria dos fragmentos florestais remanescentes encontram-se ilhados em áreas montanhosas, onde a ocupação humana é mais difícil e onde as nascentes dos cursos d'água são protegidas por lei. Neste domínio, a interação entre fatores topográficos e o tipo de cobertura vegetal pode determinar fortemente certos fenômenos e processos florestais. Por exemplo, dependendo do tipo de solo e clima, uma cobertura de gramíneas em áreas inclinadas favorece sensivelmente a ocorrência de deslizamentos de massa. De acordo com Oliveira et al. (1996), dentre as clareiras geradas por eventos extremos de chuva em 1996 no Maciço da Tijuca, a grande maioria (entre as maiores que $500 \mathrm{~m}^{2}$ ) ocorreu em áreas dominadas por floresta degradada (42\%) e gramíneas/arbustos (43\%), enquanto apenas $12 \%$ em áreas de floresta preservada. As consequências desses deslizamentos podem ser graves, pois o aumento dos fluxos de sedimentos causa assoreamento dos canais e enchentes nas baixadas, levando a mortes e proliferação de doenças. As cicatrizes que restam após os deslizamentos geram ainda efeitos de borda na vegetação do entorno que podem ser intensos, degradando-a até muitos anos depois, como sugeriram os resultados de Montezuma (2005) e Negreiros (2006). Configura-se, assim, um ciclo de retroalimentação, em que os deslizamentos degradam a vegetação por efeito de borda, favorecendo a ocorrência de novos deslizamentos.

Frente ao exposto, fica claro que a presença da vegetação de gramíneas, aliada às variações topográficas, pode acarretar grandes dificuldades tanto à preservação quanto à regeneração florestal, e, desta forma, torna-se fundamental entender seus padrões de estabelecimento e permanência, visando a gerar subsídios para futuros programas de proteção florestal e recuperação de áreas degradadas. $\mathrm{O}$ presente estudo objetivou analisar a distribuição espacial das manchas de gramíneas em uma floresta urbana montanhosa, investigando potenciais influências da topografia nesta distribuição.

\section{Área de Estudos}

O Maciço da Tijuca (Rio de Janeiro, Brasil) é um relevo montanhoso costeiro, com substrato rochoso de idade pré-cambriana, localizado na porção Leste da cidade do Rio de Janeiro, entre os paralelos $22^{\circ} 55^{\prime}$ e $23^{\circ} 00 \mathrm{~S}$ e os meridianos $43^{\circ} 20$ e $43^{\circ} 10 \mathrm{~W}$. Estende-se por aproximadamente 12.000 ha em área planimétrica, sendo que este número sobe para quase 14.000 ha em superfície real, com altitudes variando de $40 \mathrm{~m}$ (cota considerada para individualização do maciço) a $1.021 \mathrm{~m}$ (Pico da Tijuca). Sua litologia é composta principalmente por gnaisses facoidais, biotita-gnaisses, kinzigitos, ortognaisses (gnaisse Archer) e granitos (granito Favela) (Pires e Heilbron, 1989). Esta formação montanhosa é drenada por bacias hidrográficas que desaguam nos reservatórios da Baía da Guanabara, nas lagoas costeiras ou diretamente no Oceano Atlântico, formando três subsistemas hidrográficos. A região possui clima tropical de altitude (Cf, Koppen), pluviosidade média anual entre 2.000 e $2.500 \mathrm{~mm}$ (podendo variar de $1.300 \mathrm{a}+3.000 \mathrm{~mm}$ anuais, segundo dados da estação Capela Mayrink, com eventos mais extremos de chuva no verão. As temperaturas variam entre $19{ }^{\circ} \mathrm{C}$ em junho (média mínima) e $25^{\circ} \mathrm{C}$ em fevereiro (média máxima), com média anual de $22{ }^{\circ} \mathrm{C}$. A maior parte da cobertura do Maciço é florestal, mas atualmente existem muitos outros usos e coberturas vegetais, podendo-se destacar as áreas de gramíneas e de ocupação humana, seja formal ou informal (favelas). Hoje, aproximadamente 1/3 da área do Maciço é protegida pelo Parque Nacional da Tijuca (Fig. 1).

\section{Material e Métodos}

Foi elaborado um mapa de uso e cobertura vegetal com base em ortofotos aéreas 1:10.000 de 2004, adquiridas no Instituto Pereira Passos (RJ). O mapeamento foi feito por fotointerpretação, através de delimitação manual de polígonos no software ArcGis 9.2. As classes foram sendo definidas a posteriori, conforme surgisse a necessidade. É preciso esclarecer que a "Vegetação Arbóreo-Arbustiva" (para a qual usaremos a sigla "VAA") trata-se de uma classe extremamente heterogênea, criada basicamente para separar as classes "Gramínea" e "Floresta", e que não reflete necessariamente uma vegetação em sucessão, podendo constituir, em muitos casos, áreas de vegetação em pleno processo de degradação. Além das classes básicas, foram distinguidas subclasses de gramínea e VAA que pareciam ter sofrido incêndios recentemente e também subclasses de floresta e VAA que mostravam alterações estruturais como rarefação de dossel, trilhas e pequenas ocupações humanas. Para a classificação das áreas de "Ocupação Informal" (favelas), foram utilizadas como auxiliares as cartas da Prefeitura do Rio de Janeiro 1:10.000 (Instituto Pereira Passos) confeccionadas a partir de sobrevoo de 1999. 


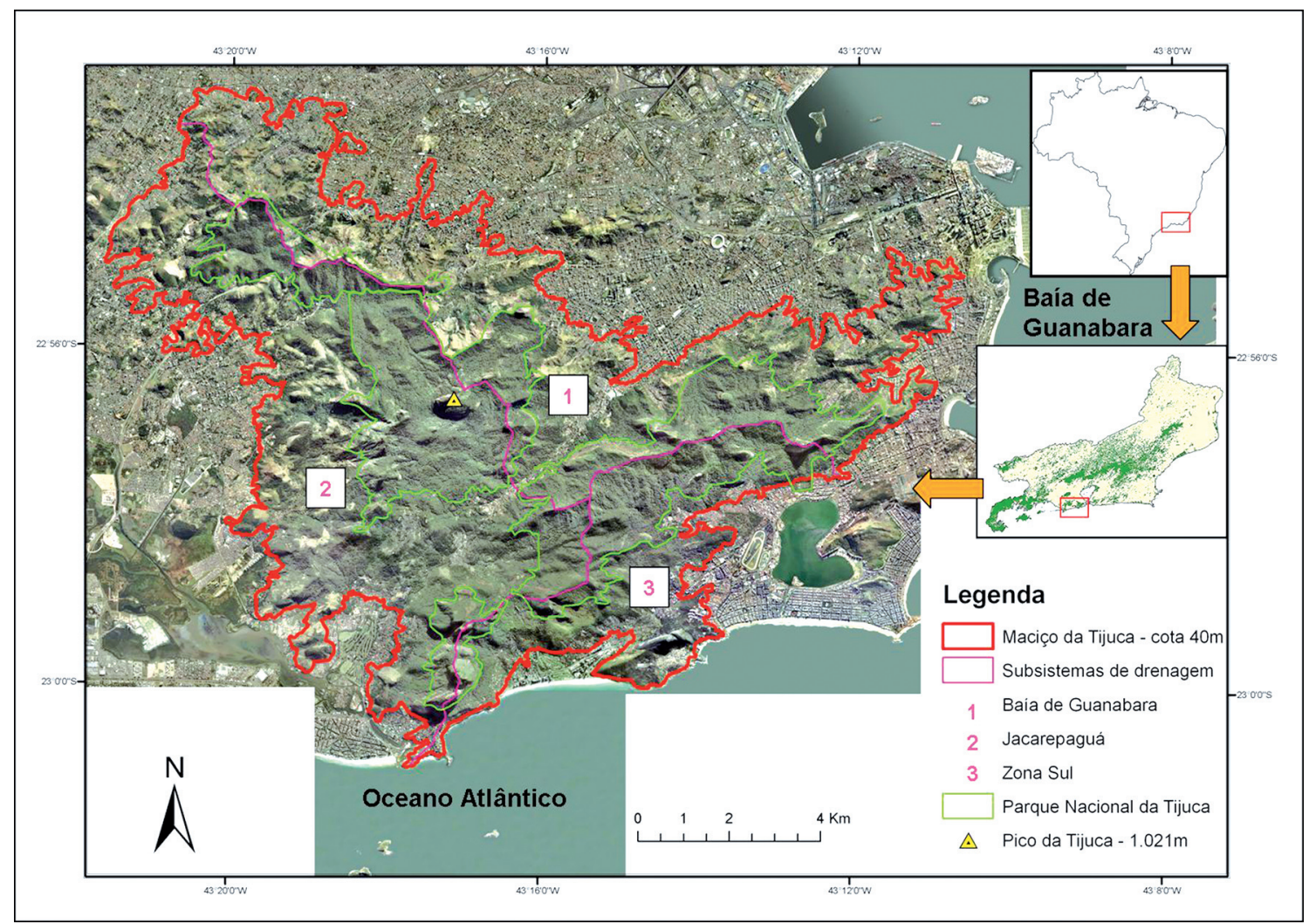

Figura 1 - Localização do Maciço da Tijuca na cidade do Rio de Janeiro.

A partir deste mapeamento e com o auxílio de um Modelo Digital de Elevação 1:10.000 (cedido pelo Pr. Dr. Manuel Fernandes, UFRJ), foram realizadas algumas análises espaciais - mensurações de área em superfície real, classificação de orientação de encostas e radiação incidente (ferramentas do ArcGis 9.2) e posição topográfica. Para a classificação da posição topográfica utilizou-se o TPI - Topographical Position Index (Jenness, 2006), uma extensão para o software ArcView 3. O mapa final resultante consistiu em uma combinação dos shapes das classes de três mapas preliminares: dois gerados pela ferramenta básica "generate slope position classification", com os diâmetros de 200 e 700 m, "on the fly" (cada mapa contendo as seis classes default - "ridge, "higher slope", "medium slope", "lower slope", "flat slope" $e$ "valley bottom"); e o terceiro mapa gerado pela ferramenta "generate landform classification" com os mesmos parâmetros (mas, neste caso, foram utilizados somente os shapes das classes extremas, "ridge" e "valley bottom").

Para as análises temporais foram feitas comparações entre mapeamentos prévios de uso e cobertura realizados sobre fotografias de 1972, 1984 e 1996 (GEOHECO-SMAC, 2000). Foi gerada também uma outra classificação de posição topográfica pelo TPI a partir de MDE compatível (o mesmo utilizado por GEOHECO-SMAC, 2000), permitindo a análise dos padrões espaciais naquelas décadas. Para análise temporal mais detalhada de bacias de segunda ordem foram comparadas ortofotos 1:10.000 de 1999 e 2004.

\section{Resultados e discussão}

\section{Uso do solo e cobertura vegetal}

O mapeamento a partir das ortofotos de 2004 resultou na criação de 12 classes (Fig. 2). Na área do Parque Nacional da Tijuca, como esperado, a cobertura florestal apresentou-se bem preservada. Já nas áreas externas ao Parque, verificou-se uma grande heterogeneidade na distribuição das classes de uso e cobertura: enquanto as vertentes Sul e Leste do Maciço permanecem, em grande parte, cobertas por floresta, as vertentes Norte e Oeste abrigam um complexo mosaico. Isto pode ser atribuído a fatores como ocupação humana mais antiga, densa e desordenada, maior exposição à poluição industrial e maior insolação na vertente Norte (subsistema hidrográfico da Baía de Guanabara) (Coelho Netto, 2005). No entanto, é preciso considerar também as menores declividades das encostas nas vertentes Norte e Oeste, o que facilita a expansão da ocupação até os dias atuais. De fato, observa-se que a heterogeneidade de usos é maior justamente na região Noroeste do Maciço, onde a inclinação das vertentes é a mais suave. As vertentes Sul e 
Leste, por outro lado, possuem encostas mais íngremes, de difícil acesso. Além disso, sua proximidade em relação ao mar leva a um aumento da especulação imobiliária, favore- cendo a ocupação formal, que, de forma geral, causa menos alterações na floresta, pois não costuma originar trilhas, desmatamentos ou incêndios para fins agropecuários.

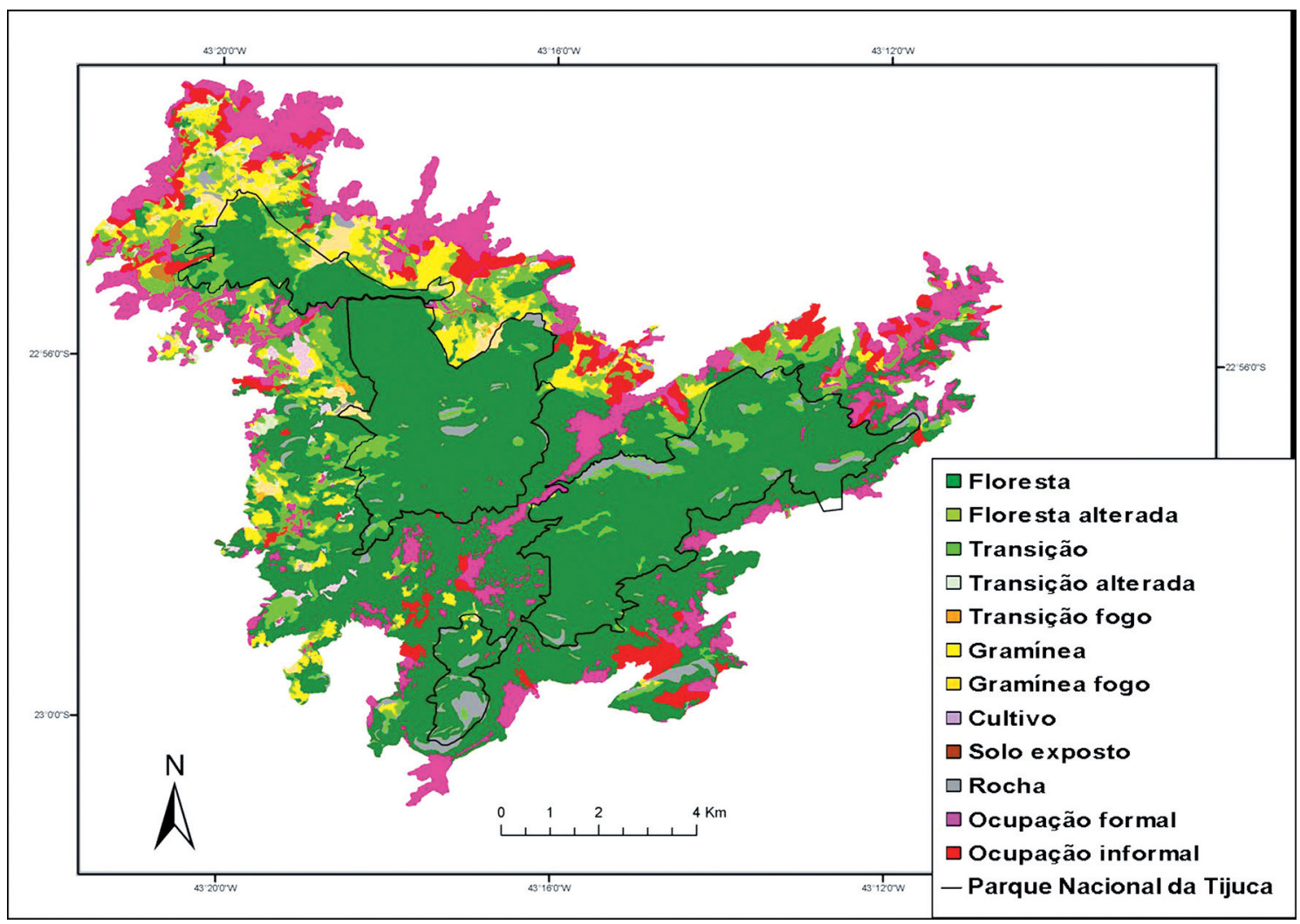

Figura 2 - Classificação de uso e cobertura do Maciço da Tijuca em 2004.

A distribuição dos tipos de uso do solo/cobertura vegetal evidenciou que, depois da classe "Floresta", há uma predominância das classes "Ocupação Formal", "Vegetação Arbóreo-arbustiva" (VAA), "Gramínea" e "Ocupação Informal (favelas)" (Tab. 1). Observa-se que a área de ocupação formal, embora seja, em geral, menos densa e acarrete, presumidamente, menor degradação florestal, é quase três vezes maior que a área de ocupação informal. Em estudo anterior, mapeamentos realizados por GEOHECO-SMAC (2000) apontaram para um preocupante crescimento da classe "Ocupação de Alta Densidade" entre 1972 e 1996. O referido estudo mostrou que tal classe era a principal a substituir a cobertura florestal no Maciço da Tijuca, mas é importante notar que ela não corresponde às favelas, usualmente consideradas as maiores responsáveis pela retração florestal no Maciço. Assim, embora a expansão desordenada de favelas se constitua, sem dúvida, como uma questão importante e que necessita controle, o efeito da expansão de áreas de urbanização formal também não pode ser menosprezado.
Tabela 1 - Distribuição da área das classes de uso e cobertura no Maciço da Tijuca em 2004.

\begin{tabular}{lcc}
\hline \multicolumn{1}{c}{ Uso / cobertura } & Área - superfície real (ha) & Área (\%) \\
\hline Floresta & 7875,96 & 56,66 \\
Ocupação formal & 1952,27 & 14,05 \\
Vegetação arbóreo-arbustiva & 1019,23 & 7,33 \\
Gramínea & 842,74 & 6,06 \\
Ocupação informal & 727,00 & 5,23 \\
Rocha & 589,25 & 4,24 \\
Floresta alterada & 445,73 & 3,21 \\
Gramínea fogo & 233,80 & 1,68 \\
Vegetação arbóreo-arbustiva alterada & 86,09 & 0,62 \\
Cultivo & 71,47 & 0,51 \\
Solo exposto & 33,54 & 0,24 \\
Vegetação arbóreo-arbustiva fogo & 22,46 & 0,16 \\
\hline
\end{tabular}

\section{Distribuição espacial}

As áreas de gramíneas e de VAA apresentaram um claro padrão de distribuição espacial, concentrando-se nas encostas voltadas para o Norte - o que foi ainda mais exacerbado para a vegetação que havia sofrido incêndios recentemente (Tab. 2). Este resultado é esperado, pois, no Hemisfério Sul, as encostas Norte recebem maior incidência de radiação solar, o que 
acarreta diferenças de umidade no (micro) clima da floresta e, consequentemente, afeta os processos geo-hidroecológicos e a suscetibilidade a incêndios. Oliveira et al. (1995) já haviam demonstrado que, no Maciço da Tijuca, encostas voltadas para o Norte possuem temperatura máxima em média $3,6^{\circ} \mathrm{C}$ maior e serapilheira com umidade $42 \%$ menor que encostas voltadas para o Sul.

Estudos em locais diversos já mostraram relações significativas entre o aspecto (orientação da encosta) e certas variáveis ecossistêmicas: Fox, Maselli e Carrega (2008) obtiveram que as encostas voltadas para o Norte, na França, tinham solos mais férteis e mais profundos, favorecendo maior crescimento da vegetação do que as encostas voltadas para o Sul e as convexidades em topos de encostas (no Hemisfério Norte as encostas Sul recebem maior radiação); similarmente, Begum et al. (2010) observaram, em florestas e áreas de agricultura no Nepal, que as encostas voltadas para o Norte apresentaram maior conteúdo de matéria orgânica, umidade, abundância e diversidade da fauna, e menor temperatura e $\mathrm{pH}$; Zeleny e Chytry (2007), no Maciço da Boêmia (República Tcheca), concluíram que o aspecto teve forte efeito na vegetação localizada na média-encosta, mas não nos fundos de vale, o que evidenciou um efeito significativo da posição topográfica; Hadley (1994) observou que encostas voltadas para o Norte no Colorado (EUA) tiveram mais rápida regeneração pós-fogo mas também maior suscetibilidade a danos por insetos, o que foi atribuído a maiores densidades de árvores "hospedeiras", maior tamanho médio das árvores e distribuição mais uniforme das árvores em áreas contíguas. $\mathrm{O}$ autor enfatizou que o aspecto e o relevo de forma geral são importantes fatores a determinar os padrões espaciais e temporais de distúrbio, sucessão e taxas de desenvolvimento local.

Tabela 2 - Distribuição das áreas de gramíneas e VAA de acordo com a orientação da encosta.

\begin{tabular}{lcc}
\hline \multicolumn{1}{c}{ Uso } & \multicolumn{2}{c}{ Área (\%) } \\
& Encostas norte & Encostas sul \\
\hline Gramínea (total) & 78,38 & 21,62 \\
Gramínea com fogo & 85,84 & 14,16 \\
Vegetação arbóreo-arbustiva (total) & 67,11 & 32,89 \\
Vegetação arbóreo-arbustiva com fogo & 78,74 & 21,26 \\
\hline
\end{tabular}

A análise de incidência de radiação solar mostrou existir forte concentração das áreas de gramíneas e VAA nas encostas que recebem alta radiação (Tab. 3) e confirmou que a grande maioria destas áreas é voltada para o Norte. Evidenciou-se também uma significativa variabilidade sazonal: no inverno, a área total de gramíneas que recebe alta radiação é $15,6 \%$ maior do que no verão, sendo que, se considerarmos somente aquelas manchas localizadas em encostas Norte, o aumento é de $29 \%$ (72,97\%, no verão, e $94,12 \%$, no inverno). Este grande percentual de áreas de gramíneas recebendo alta radiação solar indica um alto risco de incêndios, especialmente no inverno, já que esta é, naturalmente, a época menos úmida, além de ser a época em que se soltam balões na cidade do Rio de Janeiro. Embora os dados de incidência de radiação no presente estudo forneçam, por enquanto, apenas valores relativos, ainda assim dão uma boa ideia comparativa da influência da orientação de encostas na dinâmica florestal, podendo até ser mais acurados do que os simples dados de aspecto, que não levam em consideração o potencial sombreamento de umas encostas por outras.

Tabela 3 - Distribuição das áreas de gramíneas e VAA de acordo com a incidência de radiação.

\begin{tabular}{lrrrrcc}
\hline \multirow{1}{*}{ Uso } & \multicolumn{5}{c}{ Radiação incidente (\%) } \\
& Alta & \multicolumn{1}{c}{ Média } & Baixa & Alta & Média & Baixa \\
\hline Gramínea (total) & 65,23 & 32,63 & 2,14 & 75,4 & 19,38 & 5,18 \\
Gramínea com fogo & 70 & 28,3 & 1,7 & 83,1 & 13,58 & 3,28 \\
Vegetação arbóreo-arbustiva (total) & 55,99 & 40,43 & 3,58 & 65,6 & 24,81 & 9,55 \\
Vegetação arbóreo-arbustiva com fogo & 64,49 & 33,27 & 2,25 & 73,4 & 19,44 & 7,16 \\
\hline
\end{tabular}

O resultado do mapeamento de posição topográfica gerado a partir do TPI encontra-se na Fig. 3. Embora haja ainda falhas na classificação, especialmente no que diz respeito à continuidade de cristas de divisor e fundos de vale, considera-se que o resultado obtido foi bastante satisfatório para uma classificação automática, sem a qual o mapeamento de posição topográfica seria praticamente inviável.

A combinação da classificação de posição topográfica com a de uso e cobertura revelou que as manchas de gramíneas e VAA também apresentaram um forte padrão de distribuição em relação à posição na encosta, estando concentradas principalmente nos divisores e nas altas encostas (considerados em conjunto), seguidos das médias encostas e raramente em baixas encostas ou fundos de vale (Tab. 4). Este padrão também era esperado, pois um relevo montanhoso gera significativas diferenças de distribuição dos fluxos de água e nutrientes: enquanto as áreas de divisor e alta encosta constituem-se como zonas de divergência de fluxos e a média encosta como zona de transferência, a baixa encosta e o fundo de vale podem ser considerados zonas de convergência de fluxos. Nestas últimas, pode-se sugerir que a maior umidade e os pacotes de solos coluviais que tendem a ser mais espessos, estáveis e ricos em matéria orgânica facilitam o estabelecimento, a permanência e a regeneração da vegetação florestal.

Tabela 4 - Distribuição das áreas de gramíneas e VAA de acordo com a posição topográfica.

\begin{tabular}{lccc}
\hline Posição topográfica & Gramínea (área \%) & VAA (área \%) \\
\hline Divisor & \multirow{2}{*}{ Zonas de divergência } & 35,17 & 34,10 \\
Alta encosta & \multirow{2}{*}{ Zona de transferência } & 14,13 & 11,08 \\
Média encosta & 40,87 & 38,98 \\
Plano & & 0,12 & 0,07 \\
Baixa encosta & \multirow{2}{*}{ Zonas de convergência } & 5,04 & 5,45 \\
Fundo de vale & & 4,68 & 10,33 \\
\hline
\end{tabular}

* Visando a manter o conservadorismo, a classe "plano", praticamente insignificante neste Maciço montanhoso (só sendo encontrada nas baixadas da vertente Norte), foi englobada na classe de convergência de fluxos. 


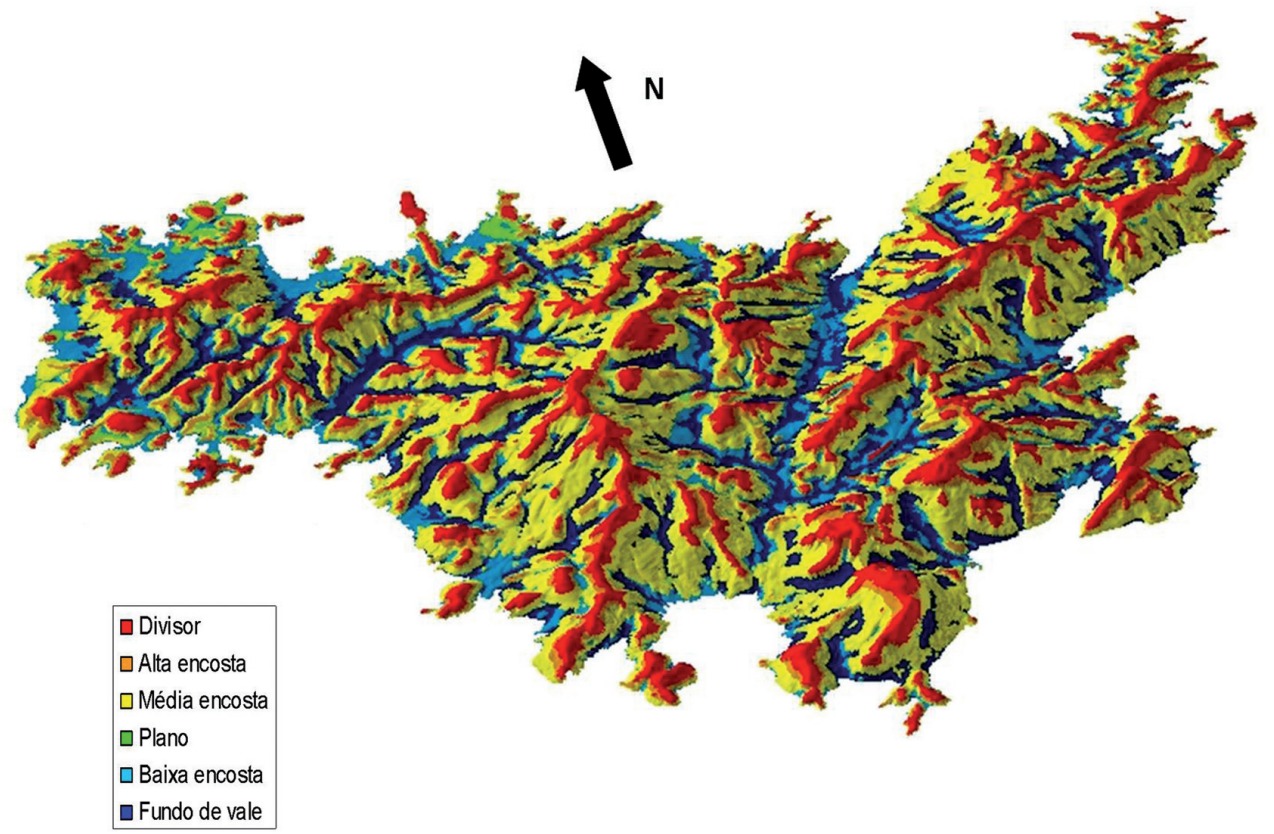

Figura 3 - Representação em 3D do mapeamento de posição topográfica gerado pelo TPI.

Embora o foco deste estudo gire em torno das áreas de gramíneas, a distribuição da VAA foi também analisada porque esta constitui a terceira maior classe em área e, comumente, se localiza entre áreas de gramíneas e de floresta, podendo representar áreas em início de sucessão ecológica. No entanto, é importante lembrar que a VAA pode constituir, inversamente, uma vegetação florestal degradada, o que impossibilita interpretações fechadas acerca dos processos geoecológicos associados à sua presença. Foi observado que, de forma geral, sua distribuição espacial costuma acompanhar a das gramíneas (Tabelas. 2, 3 e 4). Porém a VAA está ligeiramente mais presente nas áreas de convergência de fluxos (aproximadamente $16 \%$ contra cerca de $10 \%$ das gramíneas, Tab. 4), o que poderia ajudar a corroborar nossa hipótese sobre a facilitação da regeneração da vegetação florestal em zonas de convergência.

As análises espaciais realizadas indicaram que as manchas de gramíneas tendem a se concentrar em áreas com maior incidência de radiação solar e em zonas de divergência de fluxos de água e nutrientes. Isto reflete o fato de que as gramíneas constituem, de forma geral, uma família de espécies ruderais, que facilmente se estabelecem e passam a dominar em áreas abertas e degradadas. Na Mata Atlântica, normalmente seriam suprimidas pelas espécies ombrófilas ao longo da sucessão ecológica, porém, nem sempre isto ocorre. Segundo Harper et al. (2000), a magnitude e a distância do efeito de borda, e, consequentemente, a estabilidade ou instabilidade das bordas florestais, são moduladas principalmente pelo tipo e a severidade da matriz. Se as gramíneas favorecem a ocorrência de incêndios e são frequentemente usadas como pastagens (acarretando pisoteamento de plântulas pelos animais), isto pode fazer com que, ao invés de a borda florestal se expandir, permaneça estável, porém degradada, ou até se retraia, permitindo a invasão das gramíneas. De acordo com Gascon et al. (2000), quando a vegetação da borda vai se tornando degradada, existe a possibilidade de que a vegetação mais interna, inicialmente protegida, torne-se também mais exposta e sofra certo grau de degradação, expondo áreas mais internas ainda - como uma onda progressiva de influência da borda. Isto pode ocorrer quando a matriz impõe condições demasiado severas, e, em tal cenário, o efeito de borda constitui-se como um importante fator a acarretar, diretamente, a retração florestal (Gascon et al., 2000).

A ideia de que em áreas montanhosas as variações topográficas podem gerar significativas variações em diversos processos florestais vem sendo bastante corroborada pelos estudos sobre o tema. Em relação à declividade, por exemplo, Bellingham e Tanner (2000), na Jamaica, encontraram uma mortalidade de árvores maior em encostas mais declivosas. Segundo Descheemaeker et al. (2009), a inclinação da encosta restringe a acumulação de húmus, pois impede o desenvolvimento das camadas orgânicas. Clevelário Jr. 
(1988), no Maciço da Tijuca, demonstrou que a dinâmica da serapilheira - compartimento onde se encontra o maior estoque de nutrientes em florestas tropicais - difere de acordo com a topografia: nas encostas laterais, seu acúmulo no solo tende a ser maior que em fundos de vale, evidenciando uma taxa de decomposição mais lenta. Porém, como o tempo de renovação dos estoques de nutrientes na serapilheira mostrou-se menor que o tempo de renovação de sua massa, tanto em encostas íngremes como em áreas planas, o autor sugeriu que a desaceleração da decomposição nestas encostas seria muito mais um mecanismo de acúmulo de matéria orgânica do que de nutrientes. Clevelário propôs então que o folhedo, principalmente a camada $\mathrm{O}_{2}$ (folhas fragmentadas, muitas vezes inexistentes nos fundos de vale), atuaria como uma resina iônica capaz de absorver íons a partir da chuva, constituindo uma estratégia da vegetação para reter nutrientes no sistema. Este modelo sugere uma clara relação de compensação entre processos geo-hidroecológicos e posição topográfica.

Robert e Moravie (2003) enfatizaram a heterogeneidade estrutural criada em uma floresta perene úmida na Índia a partir de variações da topografia. Seu estudo mostrou que o crescimento em diâmetro das grandes árvores foi claramente maior em encostas íngremes do que em encostas suaves, enquanto o das árvores pequenas foi menor ou similar. Para um mesmo diâmetro, as árvores apresentavam-se mais altas em encostas suaves. Além disso, a distribuição espacial dos troncos era muito regular em encostas suaves, e aleatória nas íngremes. Os autores sugerem que seus resultados apontam para diferenças nos principais processos responsáveis pela dinâmica florestal: competição, estabelecimento e sobrevivência.

Em relação à posição topográfica, Herwitz e Young (1994), em uma floresta tropical montana na Austrália, descreveram que, enquanto na baixa encosta a mortalidade das árvores era balanceada por novos recrutamentos, na alta encosta ela excedia o recrutamento, evidenciando uma maior dificuldade de estabelecimento das plântulas em divisores e altas encostas. Os autores concluiram que, em seu estudo, o padrão comumente descrito de que em posições topográficas elevadas a floresta apresenta menor porte foi explicado não por menores taxas de crescimento, mas por maiores taxas de turnover (aproximadamente o dobro).

A influência da topografia nos padrões de recrutamento, crescimento e mortalidade determina, em última instância, diferenças também nos padrões florísticos de um remanescente florestal (Laurance et al., 1998). Marangon et al. (2008), em Viçosa (MG), obtiveram maior similaridade florística entre áreas planas e de ravina, quando comparadas a encostas e topos de morro. Slik e Eicchorn (2003) demonstraram a existência de uma interação entre distúrbio e topografia na criação dos padrões florísticos de uma floresta tropical na
Indonésia: em florestas que sofreram incêndios, as espéciesclímax mostraram-se mais comuns em pântanos, vales e baixas encostas, enquanto em florestas não queimadas o padrão oposto foi evidenciado (a densidade de espécies-clímax aumentou progressivamente na direção de altas encostas e divisores). As espécies pioneiras, por outro lado, foram abundantes em toda a floresta queimada, especialmente em encostas e divisores.

Os parâmetros de solo também já se mostraram correlacionados com a posição topográfica. Em uma floresta subtropical em Taiwan, Zueng-Sang Chen et al. (1997) observaram que o $\mathrm{pH}$, o cálcio e o magnésio trocáveis aumentaram na direção da baixa encosta, enquanto o alumínio trocável foi maior nos solos da alta encosta, indicando a importância dos processos de encosta na redistribuição dos minerais do solo. Já o conteúdo de nitrogênio disponível, o potássio trocável e a CTC (Capacidade de Troca Catiônica) no topo do solo (primeiros $40 \mathrm{~cm}$ ) foram consideravelmente mais baixos nos solos de florestas a barlavento. Wang et al. (2009), em Sichuan (China), notaram que os solos dos fundos de vale continham mais matéria orgânica, nitrogênio total e potássio total, entre outros nutrientes; por outro lado, o fósforo total se correlacionou com o baixo conteúdo de nutrientes nos divisores. Outros nutrientes solúveis em água foram altamente variáveis pela bacia, o que levou os autores a concluirem que a influência da topografia é nutriente-específica, gerando uma relação bastante complexa.

A influência da topografia nos processos geo-hidroecológicos já foi evidenciada também a partir de pesquisas em cicatrizes de deslizamento no Maciço da Tijuca, que demonstraram que a vegetação florestal se regenera, em uma encosta, predominantemente de baixo para cima (Montezuma, 2005; Chirol, 2003). O acúmulo de matéria orgânica e a maior umidade nas partes mais baixas da clareira favorecem a recuperação da vegetação, enquanto as partes mais altas sofrem maior erosão pela lavagem da chuva, constituindo-se como áreas de mais difícil colonização. O próprio aparecimento dessas clareiras provavelmente se relaciona fortemente à posição topográfica. Ashton et al. (2001) sustentam que os distúrbios naturais variam muito em severidade, tipo e extensão de acordo com a topografia: no Sudeste do Sri Lanka foi observado que as árvores em divisores são mais suscetíveis a secas e a quedas de raios; nas meias-encostas são mais suscetíveis a deslizamentos, especialmente em encostas mais expostas devido a diferenças de aspecto; e, nas áreas periodicamente inundáveis, perto de canais, as árvores possuem raízes mais rasas, sendo muito suscetíveis a quebras por vento canalizado nos vales. Laurance e Curran (2008) ressaltam que, apesar de áreas elevadas e a barlavento serem geralmente mais vulneráveis a ventos, ventos fortes podem interagir de formas complexas com a topografia, gerando uma forte turbulência descendente em áreas a sotavento. 
Os resultados de Lima e Moura (2008) mostraram ainda que os divisores tendem a apresentar clareiras menores e uma maior proporção de clareiras criadas por quedas de galhos, enquanto as encostas possuem clareiras maiores, geralmente criadas por rompimentos de raízes. Gale (2000), em estudo semelhante, comparou a ocorrência de clareiras baixas e clareiras altas (criadas em diferentes estratos na estrutura vertical da floresta) de acordo com a posição na encosta, altitude, inclinação e superfície rochosa. O autor observou que os platôs tinham a menor proporção de clareiras baixas, seguidos pelos vales e altas encostas, enquanto as médias encostas e os divisores tinham a menor proporção de clareiras baixas e a maior de clareiras altas. Esta distribuição apresentou razoável correlação com o tipo de queda de árvores: enquanto os divisores possuíam a menor proporção de quedas de árvores vivas e a maior de quedas de árvores mortas, os vales tinham alta proporção de quedas de árvores vivas. Gale atribuiu isto ao fato de que árvores mortas criam clareiras altas mais facilmente, por causa da fragmentação gradual, enquanto árvores vivas tombam, em geral, por inteiro.

\section{Padrões temporais}

Os padrões de distribuição espacial de gramíneas entre 1972 e 1996 mostraram-se bastante constantes e evidenciaram uma maior concentração nas médias encostas, em seguida nos divisores e altas encostas. Foi possível detectar uma ligeira tendência de aumento das áreas de gramíneas nas zonas de divergência de fluxos e diminuição nas zonas de convergência (Tab. 5), o que se soma aos resultados anteriores na corroboração da nossa hipótese de que a vegetação florestal retornaria com maior facilidade nessas zonas de convergência. Não foi possível, no entanto, comparar a transformação de uso e cobertura entre 1972 e 1996 com os padrões encontrados no mapeamento de 2004, devido à metodologia e à legenda distintas.

Tabela 5 - Transformação temporal (1972-1984-1996) das áreas de gramíneas (\%) de acordo com a posição topográfica.

\begin{tabular}{lrrr}
\hline Posição topográfica & $\mathbf{1 9 7 2}$ & $\mathbf{1 9 8 4}$ & $\mathbf{1 9 9 6}$ \\
\hline Fundo de vale + Baixa encosta + Plano & $\mathbf{2 4 , 1 7}$ & 20,31 & 18,02 \\
Média encosta & 41,19 & 42,38 & 42,81 \\
Alta encosta + Divisor & 34,64 & 37,30 & 39,16 \\
\hline
\end{tabular}

A comparação das ortofotos de 1999 com as de 2004 não mostrou, de forma geral, grande diferença de uso e cobertura. Porém, em algumas áreas específicas foi observado que as gramíneas haviam se modificado sensivelmente para uma vegetação arbóreo-arbustiva. Decidiu-se então analisar esta transformação gramíneas - VAA utilizando um recorte de bacias de segunda ordem no Maciço. Os resultados mostraram que, das 203 bacias de segunda ordem existentes, 76 possuíam gramíneas em 1999. Destas, 28 (cerca de 37\%) apresentaram alguma transformação para VAA (critério binário de análise: 0 - não transformação; 1 - transformação). Um fator não esperado foi que, destas 28 bacias, cerca de $43 \%$ apresentaram sinais de reflorestamento (curvas de nível indicando plantios). Já entre as 48 bacias consideradas sem transformação, apenas uma $(2,08 \%)$ mostrou sinais de reflorestamento. Se, por um lado, isto indica que os programas de reflorestamento vêm obtendo algum sucesso, por outro sugere que a vegetação também possui relativa capacidade de autorregeneração, pois $57 \%$ das bacias com transformação não mostraram sinais de reflorestamento. Os fatores que influenciam esta recuperação provavelmente incluem um baixo grau de severidade da matriz e alguns fatores topográficos, porém isto necessitaria de investigação no âmbito dos processos de encosta.

Uma análise em escala de maior detalhe, em dez bacias de segunda ordem selecionadas por apresentarem sensível transformação gramíneas - VAA, entre 1999 e 2004 (um exemplo de bacia mapeada é mostrado na Fig. 4), evidenciou que a diminuição das áreas de gramíneas foi proporcionalmente maior nas zonas de convergência de fluxos (Tab. 6), como esperaríamos. Por outro lado, o aumento das áreas de VAA mostrou-se proporcionalmente maior nas áreas de divergência (Tab. 6), assim como a substituição das áreas de gramíneas pelas de VAA (neste caso considerando que toda a área de gramíneas que regrediu tornou-se VAA - simplificação esta bem próxima da realidade) (Fig. 5). A substituição percentual foi de $23,3 \%$ para as zonas de convergência, $30,2 \%$ para a zona de transferência e $32,6 \%$ para as zonas de divergência. Embora trate-se de uma diferença pequena, nossas hipóteses levariam a predizer o oposto, ou seja, maiores taxas de substituição gramíneas - VAA em zonas de convergência. Tal resultado provavelmente se relaciona com os reflorestamentos realizados nas bacias analisadas, que interferem na regeneração natural, e também com a forma que essas manchas de gramíneas foram criadas e permanecem abertas (provavelmente relacionada ao fogo, que dificilmente atinge os fundos de vale). A maior diminuição proporcional das áreas de gramíneas nas zonas de convergência, por outro lado, possivelmente está refletindo um padrão natural, já que os reflorestamentos geralmente não são feitos em fundos de vale, mas principalmente nas médias e altas encostas.

\begin{tabular}{|c|c|c|c|c|}
\hline \multirow{2}{*}{ Uso } & \multirow{2}{*}{ Posição topográfica } & \multicolumn{2}{|c|}{ Área (ha) } & \multirow{2}{*}{$\begin{array}{c}\text { Diminuição (graminea) I } \\
\text { Aumento (VAA) } \\
(\%)\end{array}$} \\
\hline & & 1999 & 2004 & \\
\hline \multirow{3}{*}{ Gramínea } & Fundo de vale + Baixa encosta + Plano & 15,14 & 7,67 & 49,30 \\
\hline & Média encosta & 55,06 & 28,28 & 48,65 \\
\hline & Alta encosta + Divisor & 80,05 & 47,43 & 40,75 \\
\hline \multirow{3}{*}{$\begin{array}{l}\text { Vegetação } \\
\text { arbóreo- } \\
\text { arbustiva }\end{array}$} & Fundo de vale + Baixa encosta + Plano & 15,86 & 22,40 & 41,28 \\
\hline & Média encosta & 30,57 & 55,25 & 80,74 \\
\hline & Alta encosta + Divisor & 19,27 & 51,44 & 166,99 \\
\hline
\end{tabular}




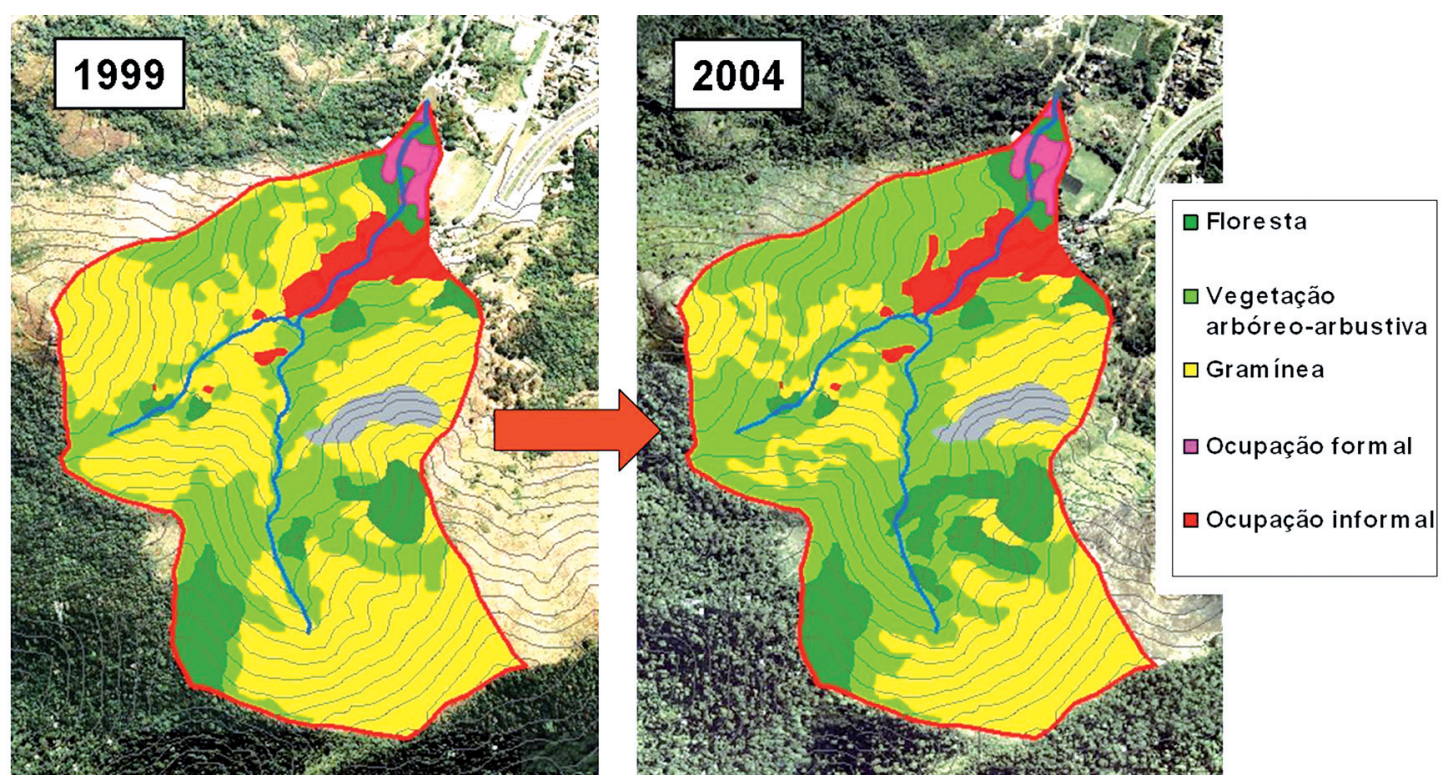

Figura 4 - Transformação do uso do solo em uma bacia de segunda ordem entre 1999 e 2004.

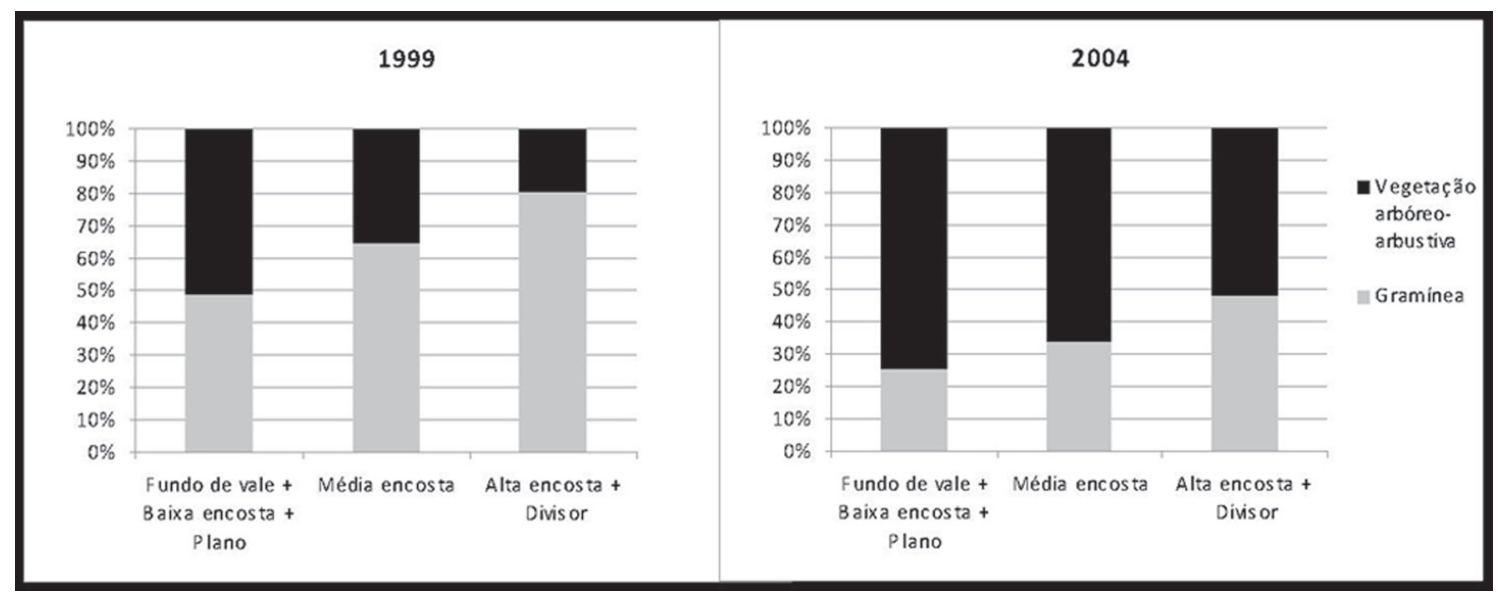

Figura 5 - Substituição percentual das áreas de gramíneas por VAA de acordo com a posição topográfica em dez bacias de segunda ordem entre 1999 e 2004.

\section{Considerações finais}

São muitas as variáveis que influenciam a distribuição da cobertura vegetal no Maciço da Tijuca. Yamagawa et al. (2006) ressaltam que fatores antrópicos podem vir a afetar a regeneração florestal mais do que fatores ambientais, como a topografia. Os resultados do presente estudo constituem apenas um primeiro passo para avaliar a possível influência da topografia, em especial a posição topográfica, na dinâmica de bordas floresta-gramíneas em zonas montanhosas na região tropical. A existência de fortes padrões espaciais (persistentes temporalmente) na distribuição das manchas de gramíneas aponta para a necessidade de investigação dos processos geo-hidro- ecológicos que ocorrem nas bordas floresta-gramíneas em diferentes situações topográficas, para a partir daí melhor compreender a dinâmica do efeito de borda e da regeneração florestal em um relevo montanhoso, assim como os efeitos do fogo recorrente favorecido pelas gramíneas. Futuras questões importantes neste contexto seriam: existe uma distância crítica do divisor (considerando a direção ascendente) a partir da qual a regeneração florestal tende a desacelerar? É possível, com base nos padrões espaciais e temporais da dinâmica de bordas floresta-gramíneas em zonas montanhosas, estimar o grau de estabilidade destas bordas? Até que ponto o fogo interfere nesta dinâmica? 


\section{Agradecimentos}

Ao Prof. Dr. Manoel Fernandes pelo fornecimento de material de base; ao pesquisador Bruno Coutinho pela introdução ao TPI; aos colegas Rogério Uagoda e Pedro Coura pela ajuda com os softwares; ao CNPq (Conselho Nacional de Desenvolvimento Científico e Tecnológico) e à FAPERJ (Fundação Carlos Chagas de Amparo à Pesquisa do Estado do Rio de Janeiro) pelo suporte financeiro; ao membro do corpo editorial da Revista Brasileira de Geomorfologia, que através da revisão contribuiu para melhorias no presente artigo.

\section{Referências bibliográficas}

ASHTON, M. S., GUNATILLEKE, C. V. S., SINGHAKUMARA, B. M. P e GUNATILLEKE, I. A. U. N. Restoration pathways for rain forest in southwest Sri Lanka: a review of concepts and models. Forest Ecology and Management 154: 409-430, 2001.

BALDISSERA, R. e GANADE, G. Predação de sementes ao longo de uma borda de Floresta Ombrófila Mista e pastagem. Acta Botânica Brasilica, v. 19 n. 1, São Paulo, 2005.

BEGUM, F., BAJRACHARYA, R. M., SHARMA, S. e SITAULA, B. K. Influence of slope aspect on soil physico-chemical and biological properties in the mid hills of central Nepal. International Journal of sustainable Development and World Ecology, vol 17, pages $438-443,2010$.

BELLINGHAM, P. J. e TANNER, E. V. J. The influence of topography o tree growth, mortality, and recruitment in a tropical montane forest. Biotropica 32:378-384, 2000.

CHEN, J.; SAUNDERS, S. C.; CROW, T. R.; NAIMAN, R. J.; BROSOFSKE, K. D.; MROZ, G. D.; BROOKSHIRE, B. L. e FRANKLIN, J. F. Microclimate in forest ecosystem and landscape ecology. Bioscience, v. 49, n. 4, p. 288-297, 1999.

CHIROL, A. A. Relações solo-fauna durante sucessão florestal em cicatrizes de movimento de massa. Dissertação de mestrado IGEO-UFRJ, 148p, 2003.

CLARK, D. B. e CLARK, D. A. Landscape-scale variation in forest structure and biomass in a tropical rain forest. Forest Ecology and Management 137: 185-198, 2000.

CLEVELÁRIO JR., J. Quantificação da massa e do reservatório de nutrientes na serapilheira da bacia do Alto Rio da Cachoeira, Parque Nacional da Tijuca, e avaliação da sua participação na ciclagem de nutrientes. Dissertação de mestrado submetida ao Programa de Pós-graduação em Geoquímica da Universidade Federal Fluminense, 1988.

COMITA, L. S., URIARTE, M., THOMPSON, J., JONCKHEERE, I., CANHAM, C. D. e ZIMMERMAN, J. K. Abiotic and biotic drivers of seedling survival in a hurricane-impacted tropical forest. Journal of Ecology 97: 1346-1359, 2009.

DESCHEEMAEKER, K., MUYS, B., NYSSEN, J., SAUWENS, W., HAILE, M., POESEN, J., RAES, D. e DECKERS, J. Humus form development during forest restoration in exclosures of the Tigray Highlands, northern Ethiopia. Restoration Ecology vol. 17, n. 2, pp. 280-289, 2009.

DIDHAM, R. K. Altered leaf-litter decomposition rates in tropical forest fragments. Oecologia 116: 397-406, 1998.
FARIA, D., MARIANO-NETO, E., MARTINI, A. M. Z., ORTIZ, J.V., MONTINGELLI, R., ROSSO, S., PACIENCIA, M. L. B. e BAUMGARTEN, J. Forest structure in a mosaic of rainforest sites: the effect of fragmentation and recovery after clear cut. Forest Ecology and Management 257: 2226-2234, 2009.

FERREIRA, L.V. e LAURANCE, W. F. Effects of forest fragmentation on mortality and damage of selected trees in central Amazonia. Conservation Biology, v. 11, p 797-801, 1997.

FIGUEIRÓ, A. S. Mudanças ambientais na interface florestacidade e propagação de efeito de borda no Maciço da Tijuca - Rio de Janeiro/RJ. Tese de doutorado - IGEO-UFRJ, 380 p., 2005.

FOX, D. M., MASELLI, F. e CARREGA, P. Using SPOT images and field sampling to map burn severity and vegetation factors affecting post fire erosion risk. Catena 75: 326-335, 2008.

FREITAS, L. E. Transformações geoecológicas, hidrológicas e erosivas em ecossistemas florestais de encosta: o papel da recorrência de incêndio. Rio de Janeiro. Dissertação (Mestrado em Geografia) - Programa de Pósgraduação em Geografia, UFRJ, 2001.

GALE, N. The relationship between canopy gaps and topography in a western Ecuadorian Rain Forest. Biotropica 32(4a): 653-661, 2000.

GASCON, C., WILliAMSON, G. B. e FONSECA, G. A. B. Receding forest edges and vanishing reserves. Science 288: 13561358, 2000.

GEOHECO-SMAC-RJ. Estudos de qualidade ambiental do geoecossistema do Maciço da Tijuca: subsídios à regulamentação daAPARU do Alto da Boa Vista. Relatório técnico, coordenado por Coelho Netto, A.L. e Secretaria de Meio Ambiente da Prefeitura do Rio de Janeiro, vol. 2. 155pp, 2000.

GONZALEZ, M., DECONCHAT, M. e BALENT, G. Woody plant composition of forest layers: the importance of environmental conditions and spatial configuration. Plant Ecology, DOI 10.1007/ s11258-009-9572-9. (publicado online), 2009.

HADLEY, K. S. The role of disturbance, topography, and forest structure in the development of a montane forest landscape. Bulletin of the Torrey Botanical Club, vol. 21, n. 1, pp. 47-61, 1994.

HARPER, K. A., MACDONALD, S. E., BURTON, P. J., CHEN, J., BROSOFSKE, K. D., SAUNDERS, S. C., EUSKIRCHEN, E. S., ROBERTS, D., JAITEH, M. S. e ESSEEN, P. Edge influence os forest structure and composition in fragmented landscapes. Conservation Biology, v. 19, n. 3, p. 768-782, 2005.

HEITHECKER, T. D. e HALPERN, C. B. Edge-related gradients in microclimate in forest aggregates following structural retention harvests in western Washington. Forest Ecology and Management 248: 163-173, 2007.

HERBST, M., ROBERTS, J. M., ROSIER, P. T. W., TAYLOR, M. E. e GOWING, D. J. Edge effects and forest water use: a field study in a mixed deciduous woodland. Forest Ecology and Management 250: 176-186, 2007.

HERWITZ, S. R. e YOUNG, S. S. Mortality, recruitment, and growth rates of montane tropical rain forest canopy trees on Mount Bellenden-Ker, northeast Queensland, Australia. Biotropica 26:350361, 1994.

JENNESS, J. Topographic Position Index (tpi_jen.avx) extension for ArcView 3.x, v. 1.2. Jenness Enterprises. Available at:http://www. jennessent.com/arcview/tpi.htm, 2006. 
JOSE, S., GILLESPIE, A. R., GEORGE, S. J. e KUMAR, B. M. Vegetation responses along edge-to-interior gradients in a high altitude tropical forest in peninsular India. Forest Ecology and Management 87: 51-62, 1996.

JULES, E. S. e PRIYA, S. A broader ecological context to habitat fragmentation: why matrix habitat is more important than we thought. Journal of vegetation Science 14: 459-464, 2003.

LAURANCE, W. F., FERREIRA, L.V., RANKIN-DE-MERONA, J. M. e LAURANCE, S. G. Rain forest fragmentation and the dynamics of Amazonian tree communities. Ecology 79:2032-2040, 1998a.

LAURANCE, W.F., FERREIRA, L.V., RANKIN-DE-MERONA, J. M., LAURANCE, S., HUTCHINGS, R.W e LOVEJOY, T. Effects of forest fragmentation on recruitment patterns in Amazonian tree communities. Conservation Biology, v. 12 n. 2: 460-464, 1998 b.

LAURANCE, W. F. Do edge effects occur over large spatial scales? Tree, v. 15, n. 4, 2000.

LAURANCE, W. F., DELARMÔNICA, P., LAURANCE, S. G., VASCONCELOS, H. Le LOVEJOY, T. E. Rainforest fragmentation kills big trees. Nature, v. 404, p. 836, 2000.

LAURANCE, W. F.; NASCIMENTO, H. E. M.; LAURANCE, S. G.; ANDRADE, A. C.; FEARNSIDE, P. M.; RIBEIRO, J. E. L., e CAPRETZ, R. L. Rain Forest Fragmentation and the Proliferation of Successional Trees. Ecology 87 (2): 469-482, 2006.

LAURANCE, W. F. Theory meets reality: how habitat fragmentation research has transcended island biogeographic theory. Biological Conservation 141: 1731-1744, 2008.

LAURANCE, W. F. e CURRAN, T. J. Impacts of Wind disturbance on fragmented tropícal forests: a review and synthesis. Austral Ecology 33: 399-408, 2008.

LI, FENG-RUI, ZHAO, LI-YA, ZHANG, HUA, LIU, JI-LIANG, LU, HAI-YAN e KANG, LING-FEN. Habitat degradation, topography and rainfall variability interact to determine seed distribution and recruitment in a sand dune grassland. Journal of Vegetation Science 20: 847-859, 2009.

LIMA, R. A. F. e MOURA, L. C. Canopy gap colonization in the Atlantic Montane Rain Forest. Brazilian Archives of Biology and Technology 49: 953-965, 2006.

LIMA, R. A. F. e MOURA, L. C. Gap disturbance regime and composition in the Atlantic Montane Rain Forest: the influence of topography. Plant Ecology 197:239-253, 2008.

MARANGON, L. C., SOARES, J. J., FELICIANO, A. L. P. e SILVA BRANDÃO, C. F. L. Regeneração natural em um fragmento de floresta estacional semidecidual em Viçosa, Minas Gerais. Revista Árvore, vol. 32, n. 1, 2008.

MONTEZUMA, R. C. M. Produção e reabilitação funcional do piso florestal em clareira de deslizamento - Parque Nacional da Tijuca, Rio de Janeiro. Tese de doutorado - IGEO-UFRJ, 294p, (2008), 2005.

MURCIA, C. Edge effects in fragmented forests: implications for conservation. Tree, v. 10, n. 2, p. 58-62, 1995.

NELSON, C. R. e HALPERN, C. B. Edge-related responses of understory plants to aggregated retention harvest in the Pacific Northwest. Ecological Applications, 15(1): 196-209, 2005.

NEGREIROS, A. B. Respostas geohidroecológicas em clareira de deslizamento numa encosta florestada: Alto Rio dos Macacos, Maciço da Tijuca (RJ). Dissertação de mestrado - IGEO-UFRJ, 88p, 2006.
OLIVEIRA, R. R., ZAÚ, A. S., LIMA, D. F., SILVA, M. B. R., VIANNA, M. C., SODRÉ, D. O. e SAMPAIO, P. D. Significado ecológico da orientação de encostas no Maciço da Tijuca, Rio de Janeiro. Oecologia Brasiliensis, PPGG-UFRJ, v. 1, 1995.

OLIVEIRA, R. R., AVELAR, A. S., LEÃO, O. M. R., FREITAS, M. M. e COELHO NETTO, A. L. Degradação da floresta e desabamentos ocorridos em fevereiro de 1996 no Maciço da Tijuca/RJ. Anais do XLVII CONGRESSO NACIONALDE BOTÂNICA, Nova Friburgo (RJ), vol. 1, p. 353-353, 1996.

PIRES, F. R. M. e HEILBRON, M. L. Estruturação e estratigrafia dos gnaisses do Rio de Janeiro/RJ. IN: SIMPÓSIO DE GEOLOGIADO SUDESTE, 1. Rio de Janeiro. Boletim de Resumos. Rio de Janeiro, SBG. p:149-150, 1989.

PORTELA, R. C. Q. e DOS SANTOS, F. A. M. Produção e espessura da serapilheira na borda e interior de fragmentos florestais de Mata Attântica de diferentes tamanhos. Revista Brasil. Bot. Vol. 30, n. 2, p. 271-280, 2007.

RIES, L., FLETCHER, R. J., BATTIN, J. e SISK, T. D. Ecological responses to habitat edges: mechanisms, models, and variability explained. Annu. Rev. Ecol. Evol. Sust. 35: 491-522, 2004.

ROBERT, A. e MORAVIE, M-A. Topographic variation and stand heterogeneity in a wet evergreen forest of India. Journal of Tropical Ecology 19: 697-707, 2003.

SIZER, N. e TANNER, E. V.J. Responses of woody plant seedlings to edge formation in a lowland tropical rainforest, Amazonia. Biological Conservation 91: 135-142, 1999.

SIZER, N. C., TANNER, E. V. J. e FERRAZ, I. D. K. Edge effects on litterfall mass and nutrient concentrations in forest fragments in central Amazonia. Journal of Tropical Ecology 16: 853-863, 2000.

SLIK, J. W. F. e EICCHORN, K. A. O. Fire survival of lowland tropical rain forest trees in relation to stem diameter and topographic position. Oecologia 137: 446-455, 2003.

TABARELLI, M., MANTOVANI, W. e PERES, C. A. Effects of habitat fragmentation on plant guild structure in the montane Atlantic forest of southeastern Brazil. Biological Conservation 91: 119-127, 1999.

WANG, H. J., SHI, X. Z., YU, D. S., WEINDORF, D. C., HUANG, B., SUN, W. X., RITSEMA, C. J. e MILNE, E. Factors determinig soil nutrient distribution in a small-scaled watershed in the purple soil region of Sichuan Province, China. Soil and Tillage Research 105: 300-306, 2009.

YAMAGAWA, H., ITO, S., MITSUDA, Y. e FUKUZATO, K. Effects of topography and management history on natural forest recovery in abandoned forest forest after clear-cutting in Miyazaki, Japan. Journal of Forest Research, vol. 11, n. 2, pp 99-106, 2006.

ZAÚ, A. S. Variação da cobertura vegetal e efeitos na hidrologia superficial: Maciço da Tijuca/RJ. Rio de Janeiro. Dissertação (mestrado em Geografia) - PPGG, UFRJ, 1994.

ZELENY,D. e CHYTRY, M. Environmental control of the vegetation pattern in deep river valleys of the Bohemian Massif. Preslia, vol 79, n 3, pp 205-222, 2007.

ZUENG-SANG CHEN, CHANG-FU HSIEH, FEEI-YU JIANG, TSUNG-HSIN HSIEH e I-FANG SUN. Relations of soil properties to topography and vegetation in a subtropical rain forest in southern Taiwan. Plant Ecology 132: 229-241, 1997. 